\title{
Railway Reservation and Route optimization System
}

\author{
Harshvardhan Mishra, Renuka Sharma
}

\begin{abstract}
The present invention relates to railway reservation and route optimisation system. Nowadays Railway is the best way to travel for long journey as compared to others. This way of transportation is cost effective and appropriate for travelling. For travelling by railways there is a requirement of advanced reservation. In the situation of emergency travelling there exists a tatkal mode to prevent passenger from alternative agents who demand large amount for tickets, for this there is a need to implement a system application for reservation tickets. A platform for those who don't want to go to ticket counter and purchase tickets has be implemented by which one can book the ticket, cancel the ticket, check the PNR status, check the best train to travel, and other suggestions related to reservation. All these aspects are explained in the present paper.
\end{abstract}

Index Terms - RAD model, Live status, Trains between start and end point, PNR.

\section{INTRODUCTION}

Today travelling has become priority for population, thus railway transport is in demand. It also helps in assisting the passenger to recognize trains with the straight path, therefore the passenger would reach to the end point with an ease and rapidly. This makes the system passenger friendly with the development of a better interface. By finding the shortest path between starting point and destination it becomes easy for a passenger to select a route. The passenger is able to know the information about the location of train. Passenger can get all the information like confirmation of ticket of if it is in waiting by the PNR number.

Maximum of the countries have railway services all over the world. Though, a passenger friendly, trustworthy and fast services always needed. As the number of passengers and shipping load are increasing day by day, therefore there is a need to develop more well-organized mechanisms for this increment. The smart system for railways can be obtained by introducing new technologies in the system. Smart computing approach can be employment in the system to make the system effective. Managing data related to passenger is the main point in the system. Detailed data of various passenger is needed mostly in the case of reservation. processing and storing should be done smoothly and very fast. In Indian railways introduction of aadhar card modified the system for manual entry of passenger details, this would also make the system secure.

There exist an e-booking system for booking tickets, there

Harshvardhan Mishra, Department of Computer Science \& Engineering, Noida Institute of Engineering and Technology, UttarPradesh, India. (Email: researchnietip@gmail.com)

Renuka Sharma, Department of Computer Science \& Engineering, Noida Institute of Engineering and Technology, UttarPradesh, India. (Email: researchnietip@gmail.com) For effectiveness of the system the process of managing data,

Revised Version Manuscript Received on 10 September, 2019.

are some feature like selecting the tickets according to availability of the seats, checking the route of the train, cancelation of tickets. The description in present method is when there exists so many routes between the start point and end point, then the passenger would get the lowest routes to the destination (end point) and that would result in time saving of the passenger. In the present paper we have used 'RAD process model', by presumptuous passenger's necessities an application has been established, thus all the necessities of passengers can be fulfilled.

In the paper a 'Rapid Application Development process model' has been used and according to the traditional view in that we have tried to apply all necessities and every passenger must use it. Today electronic devices are used by everyone which are running with time but there exists some people that are not much aware of the technologies and they can't use them effectively. The presented application would help these kind of people quite effectively[1][2].

In paper [7] it is explained that basic facilities are provided by railways are good food availability, enquiry facility, good sanitation etc. All these facilities attract users and increase the number of passengers, Present reservation system doesn't have a facility to choose seats according to their need, Thus members of same family get seats in other coaches.

The section 2 of the paper is methodology, and 3rd section discloses about present work. Section 4 explains the implementation of the application and then whole work is followed by the conclusion.

\section{METHODOLOGY}

An incremental type model has been established for Railway Reservation to entree all the features and the system is a user friendly system. According to the requirements of the user each and every group comprises a module that has dissimilar operations. The designing uses a segmental and an operational method wherein the whole code would be divided in various modules or operations and can be fetched according to the requirement. In this application an Android studio has been used wherein the requirements of user are pre-assumed and implemented in 'XML' language and each and every module would be jointed together by employing 'java' language then the modules would be associated with API's and then data could be delivered after raising a request by the user(s). The main operations are, obtaining and observing the main concerns of the user during booking or when other queries like the ticket cancellation, Status of PNR, information about train, live status of train and when there's a difficulty encountered by the user, for this case a contact information has been given so that user(s) would be able to make the problems to be known by the attendant.

Published By:

Blue Eyes Intelligence Engineering 
After developing each module, they're jointed together to make the requisite application. In combination to the regular operations the optimization of shortest path has been meant to provide information about train that reaches via the shortest route that would result in saving time to reach the end point in less time from all the existing trains. The system is entirely depend on RAD, thus the user necessities have been presumed and implemented the application. Every necessity may not be fulfilled, however the necessities presumed would be fulfilled in finest manner. In the application the user side includes some options like ticket booking, ticket cancelling, PNR status checking, live checking of train's status, information about train although the options for the server side are providing data to different users according to the demand by the user in API's form which is an 'Application Programming Interface'.

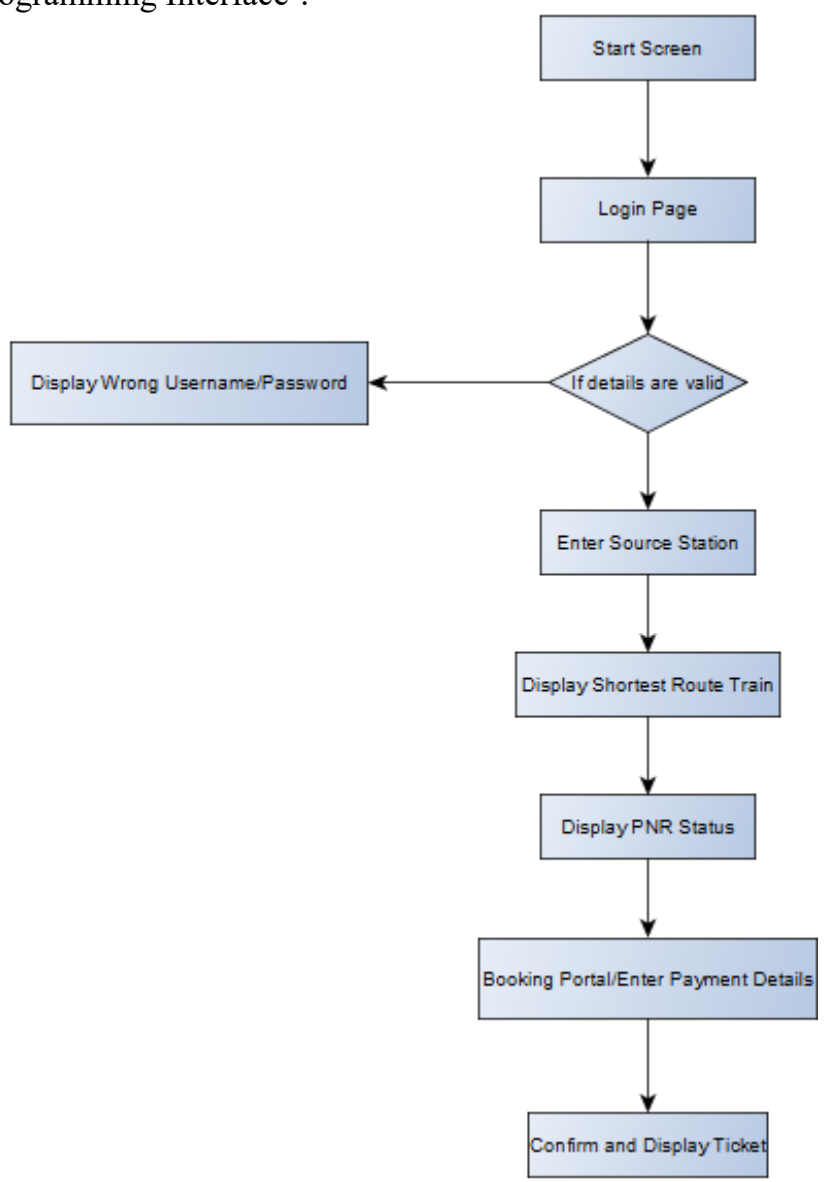

Figure 1 Flow chart of user interface

It is known that various applications exist with all the features like booking, however everyone is aware of all other features but the presented application that has been developed would be newer the user(s) and would help the user(s) that do not even have simple awareness of whole features, can use this application because of an interface which is user friendly, additional feature can also be used. It gives proposals to the users about the train like this train would reach in smallest time period to the end point (destination). Features that make the application novel are explained in the 3rd section of the paper. The application's overview has been given, in Figure 2. From the figure it can be seen the process for retrieving of application's all features. The Figure 2 represents an overview for the application.

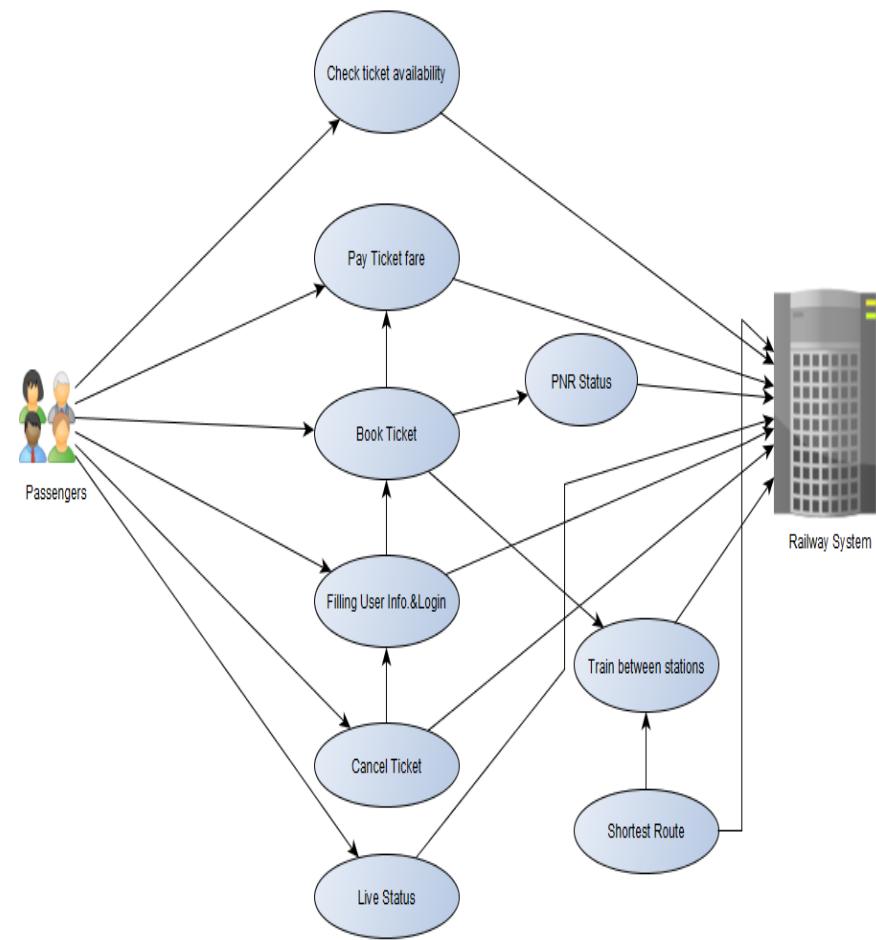

Figure 2 Application Overview

\section{PRESENT WORK}

Though IRCTC includes so many features but it cannot be identified that which train in the smallest time period reaches the end point (Destination). With the use of IRCTC person would fetch a list of trains that are available from current place to the end point. Without comparing times of different trains to reach the destination, it is not possible to know that which train would reach faster in the shortest time interval.

Nowadays everyone desire to reach the destination as fast as possible. When the person selects train to travel that he/she should be aware about all the information of train like which train would help in reaching him/her earliest. Thus, one additional feature has been added to the existing one and one can easily get to know that which train is a best option to reach. Some sorting algorithms have been employed with some circumstances. Time for all the trains have been sorted. Then by selecting the present time we can know which trains are available. When the 1st train isn't available, the system would move further on to the successive train and this goes would continue. In this way the system can help the user in effective manner. The result of all these methods is that, it would show the train among all the trains at the top of the list which is taking less time to reach the destination.

\section{IMPLEMENTATION\& RESULTS}

An application for railways has been implemented by employing Android via which all the modules have been written in 'XML' language. Every module is used in a combination by employing 'java' language and there are some photos to represent the projected application and the pictures demonstrate operation of the application: 


\section{liveStatus}

\begin{tabular}{|c|c|c|}
\hline Howrah Express & 07256 & Reached \\
\hline $02: 05$ & $01: 30$ & Guntur Jn \\
\hline Vijayawada Jn & & \\
\hline
\end{tabular}

Figure 3 Live status of train

\section{Railway App}

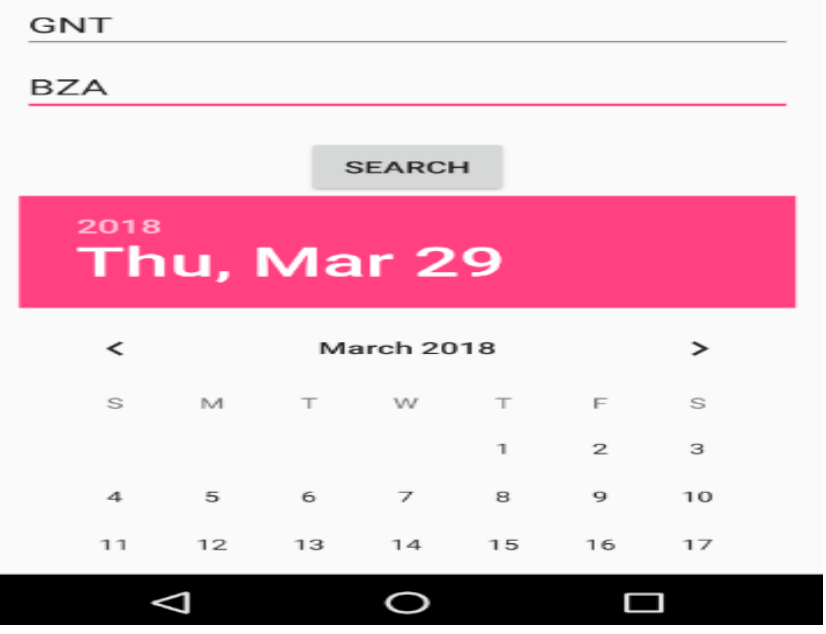

Figure 4 Search between 2 stations

\begin{tabular}{l} 
Suggestion box: Shortest time \\
HYB-NS EXP \\
Time Taken03:15 \\
HYB-NS EXP \\
Trainn No: 17256 \\
Starting Time01:20 \\
Ending Time:04:35 \\
Time Taken:03:15 \\
UBL-BZA AMARAVATI EXP \\
Trainn No: 17226 \\
Starting Time01:40 \\
Ending Time:05:15 \\
Time Taken:03:35 \\
YPR-BZA PASS \\
Trainn No: 56503 \\
Starting Time01:30 \\
Ending Time:05:55 \\
Time Taken:04:25 \\
\hline$<$
\end{tabular}

Figure 5 Train suggestion

\section{PNR Check}

12734 Narayanadri Express

Check Route

$3 \mathrm{~A}$

Guntur Jn

Tiprupathi
GNT

田

23:10

06:05

$\begin{array}{llll}\text { S.No } & \text { Booking } & \text { Current } & \text { Berth } \\ 1 & \text { S8,39 } & \text { S8,39 } & \end{array}$

Figure 6 PNR checking

\section{V.CONCLUSION}

An application for railways have been developed for satisfying user requirements successfully. The application provides addition information like which train for a particular route will be best mode to travel and reach the destination along with the informations like checking of PNR status, ticket booking, cancellation of tickets etc. The application has been implemented in order to help user to fulfill all user requirement in a better way. The presumption have been made by this to fulfill all the necessities of user. It is observed that system is user friendly and helpful for those who don't even have much knowledge about technologies as the searching is not complicated in this.

\section{REFERENCES}

1. B. T. T. S. Sakthi, J. J. Leo, R. Monisha, and S. M. Ramesh, “Advanced train reservation and passenger intimation with safety system," in 2014 International Conference on Information Communication and Embedded Systems, ICICES 2014, 2015.

2. K. Ganesh, M. Thrivikraman, J. Kuri, H. Dagale, G. Sudhakar, and S. Sanyal, "Implementation of a Real Time Passenger Information System,” Int. J. Eng. Sci. Manag., 2012.

3. T. Xin et al., "Railway vertical alignment optimisation at stations to minimise energy," in 2014 17th IEEE International Conference on Intelligent Transportation Systems, ITSC 2014, 2014.

4. Q. Xu, H. Ji, X. Li, and H. Zhang, "Admission Control Scheme for Service Dropping Performance Improvement in High-Speed Railway Communication Systems," in IEEE Transactions on Vehicular Technology, 2016.

5. P. Chowdhury, P. Bala, D. Addy, S. Giri, and A. R. Chaudhuri, "RFID and Android based smart ticketing and destination announcement system," in 2016 International Conference on Advances in Computing, Communications and Informatics, ICACCI 2016, 2016.

6. M. M. Dessouky, Q. Lu, J. Zhao, and R. C. Leachman, "An exact solution procedure to determine the optimal dispatching times for complex rail networks," IIE Trans. (Institute Ind. Eng., 2006.

7. S.Vishnuvarthani, Dr.A.Selvaraj(October 2012), "Factors Influencing the Passengers to Select Train Travel: A Study in Salem Division of Southern Railway", International Journal of Scientific and Research Publications, Volume 2, Issue 10.

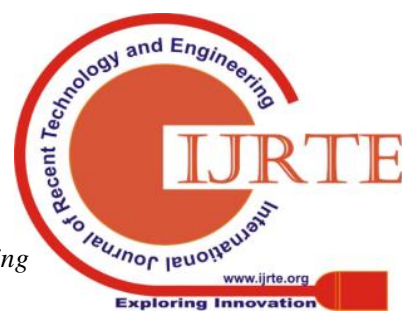

